\title{
Discussions about the Predictor and Outcome of Transfusion Therapy for Earthquake Patients
}

\author{
Yaqi Chen, $\mathrm{MB} ;{ }^{1,2} \odot$ Hai $\mathrm{Hu}, \mathrm{MD}, \mathrm{PhD} ;{ }^{2,3,4} \odot$ Chengrun Song, $\mathrm{MB}^{1,2} \odot$
}

1. West China School of Medicine, Sichuan University, Chengdu, China

2. West China Association of Disaster Medicine, Sichuan University, Chengdu, China

3. Emergency Office of West China Hospital, Sichuan University, Chengdu, China

4. China International Emergency Medical Team (Sichuan), Chengdu, China

\section{Correspondence:}

Hai $\mathrm{Hu}, \mathrm{MD}, \mathrm{PhD}$

No.37 Guoxuexiang Road

Wuhou District, Chengdu City

Sichuan Province, PR China

E-mail: whowasyoung@hotmail.com

Conflicts of interest/disclaimer: The views expressed in the submitted article are the authors' and not an official position of the institution or funder. Each author has declared no conflict of interest.

Keywords: disaster; earthquake; transfusion

\section{Abbreviations:}

FAST: Focused Assessment Sonograph for Trauma

GCS: Glasgow Coma Scale

HR: heart rate

ICU: intensive care unit

RBC: red blood cell

SBP: systolic blood pressure

SI: Shock Index

Received: March 24, 2021

Revised: May 24, 2021

Accepted: May 24, 2021

\section{doi:10.1017/S1049023X21000741}

(C) The Author(s), 2021. Published by Cambridge University Press on behalf of the World Association for Disaster and Emergency Medicine.
Chen Y, Hu H, Song C. Discussions about the predictor and outcome of transfusion therapy for earthquake patients. Prehosp Disaster Med. 2021;36(5):654-656.

To the Editor,

We read with great interest the article by Michalsen, et al regarding the "Prehospital Transfusion of Red Blood Cells and Plasma by an Urban Ground-Based Critical Care Team." It is inspiring to find prehospital blood component therapy is feasible to significantly improve patient physiology and degree of shock.

However, unlike the happening of individual traumatic injury or non-traumatic bleeding recorded in the original article, blood products are in short supply, especially when large-scale disaster events occur like earthquakes. ${ }^{2}$ Considering the difficulty to implement prehospital transfusion treatment, supplement of blood products in-hospital remains an indispensable step in emergency rescue to severely injured patients. But few studies analyzing predictors and clinical outcomes of transfusion focused on earthquake patients with specific characteristics of casualties. To reveal predictors and outcomes of transfusion in earthquake in-patients, we did a retrospective study with patients from West China Earthquake Patients Database.

The information we collected included personal demographic data, transfusion therapy (whole blood, red blood cell [RBC], or plasma), mechanism of injury, and detailed data of performed standard diagnostic procedures (clinical, radiological, and laboratory tests). We chose Shock Index (SI; defined by the ratio of heart rate [HR] to systolic blood pressure [SBP]), hemoglobin level, Glasgow Coma Scale (GCS), and Focused Assessment Sonograph for Trauma (FAST) as possible predictors of transfusion. Outcomes were coagulopathy, as a common complication of transfusion, admission to intensive care unit (ICU), and death. T-test, Kruskal-Wallis test, and Chi-squared test were used for the tends to reveal the possible association between a chosen predictor or outcome and transfusion therapy. P values $<.05$ were considered significant in this study. All statistical analyses were performed using SPSS version 20.0 software (IBM Corp.; Armon, New York USA). Human Research Subjects Ethics Committee review was by the Ethics Committee on Biomedical Research, West China Hospital of Sichuan University (Chengdu, China; protocol number: 2020-477).

Excluding records with missing basic information $(n=87)$, missing laboratory data $(n=9,323)$, missing transfusion information $(n=67)$, and missing outcome data $(n=3,716)$, a total of 23,411 cases were enrolled in this study finally. Among all patients included, 2,563 patients received transfusion treatment; 336 of them received whole blood; 2,086 received RBC; 1,272 received plasma; and 177 received massive transfusion (defined as the provision of $\geq 10$ units $\mathrm{RBC}$ within 24 hours after admission). The mean age of the transfused was 48.7 (range 1-103) years with 1,095 males (43.2\%). The most common mechanism of injury was blunt force injury $(n=1,893)$ followed by contusion $(\mathrm{n}=1,147$; Table 1$)$.

For patients who received any transfusion, the mean (standard deviation) hemoglobin was $109.48(\mathrm{SD}=39.461) \mathrm{mg} / \mathrm{L}$, and the median (interquartile range) for SI was 0.71 $(0.62-0.84)$ and $15(15-15)$ for GCS, with 158 (6.23\%) found FAST positive. Surprisingly, the transfusion group was found with higher SI, lower GCS, and FAST positive $(\mathrm{P}<.001)$ compared with those who had not received transfusion therapy. No significant difference was found regarding hemoglobin level between these two groups $(\mathrm{P}=.461)$, and only $372(14.51 \%)$ met the recommended target level hemoglobin of $7 \mathrm{~g} / \mathrm{dl}$ to $9 \mathrm{~g} / \mathrm{dl}$ mentioned in the original article. For outcomes, the transfused 


\begin{tabular}{|c|c|}
\hline No. of Patients & 2,536 \\
\hline Male Sex, n (\%) & $1,095(43.2 \%)$ \\
\hline Mean Age, Years (range) & $48.7(1-103)$ \\
\hline \multicolumn{2}{|l|}{ Transfusion Administered } \\
\hline - Whole Blood only, n (\%) & $169(6.67 \%)$ \\
\hline - RBC only, $\mathrm{n}(\%)$ & $1,026(40.46 \%)$ \\
\hline - Plasma only, $\mathrm{n}(\%)$ & $227(8.95 \%)$ \\
\hline - Whole Blood \& RBC, n (\%) & $69(2.72 \%)$ \\
\hline - Whole Blood \& Plasma, n (\%) & $54(2.13 \%)$ \\
\hline - RBC \& Plasma, n (\%) & $917(36.16 \%)$ \\
\hline - Whole Blood \& RBC \& Plasma, n (\%) & $74(2.92 \%)$ \\
\hline \multicolumn{2}{|l|}{ Mechanism of Injury ${ }^{a}$} \\
\hline - Blunt Force Injury, n (\%) & $1,893(74.65 \%)$ \\
\hline - Contusion, n (\%) & $1,147(45.23 \%)$ \\
\hline - Laceration, $\mathrm{n}(\%)$ & $611(24.09 \%)$ \\
\hline - Abrasion, n (\%) & $432(17.03 \%)$ \\
\hline - Destructive Injury, n (\%) & $179(7.06 \%)$ \\
\hline - Puncture Injury, n (\%) & $20(0.79 \%)$ \\
\hline - Penetrating Injury, n (\%) & $11(0.43 \%)$ \\
\hline - Other, n (\%) & $313(12.34 \%)$ \\
\hline
\end{tabular}

Table 1. Characteristics of Patients Receiving Transfusion Therapy

a A patient might have combined mechanism of injury.

\begin{tabular}{|c|c|c|c|c|c|c|c|}
\hline & & \multicolumn{2}{|c|}{$\begin{array}{c}\text { Transfusion } \\
(\mathrm{n}=2,536)\end{array}$} & \multicolumn{2}{|c|}{$\begin{array}{c}\text { No Transfusion } \\
(n=20,875)\end{array}$} & \multirow{2}{*}{$\chi^{2}$} & \multirow[t]{2}{*}{ P Value } \\
\hline \multicolumn{2}{|l|}{ Outcomes } & Number & $\%$ & Number & $\%$ & & \\
\hline \multirow[t]{2}{*}{ Coagulopathy } & Yes & 901 & 35.53 & 4,525 & 21.68 & \multirow[t]{2}{*}{243.667} & \multirow[t]{2}{*}{.000} \\
\hline & No & 1,635 & 64.47 & 16,350 & 78.32 & & \\
\hline \multirow{2}{*}{$\begin{array}{l}\text { Admission to } \\
\text { ICU }\end{array}$} & Yes & 409 & 16.13 & 290 & 1.39 & \multirow[t]{2}{*}{1695.790} & \multirow[t]{2}{*}{.000} \\
\hline & No & 2,127 & 83.87 & 20,585 & 98.61 & & \\
\hline \multirow[t]{2}{*}{ Death } & Yes & 60 & 2.37 & 90 & 0.43 & \multirow[t]{2}{*}{132.967} & \multirow[t]{2}{*}{.000} \\
\hline & No & 2,476 & 97.63 & 20,785 & 99.57 & & \\
\hline
\end{tabular}

Table 2. Outcomes of Patients Received Transfusion Therapy or Not

Chen (c) 2021 Prehospital and Disaster Medicine Abbreviation: ICU, intensive care unit.

were found to have a higher proportion of coagulopathy, admission to ICU, and death $(\mathrm{P}<.001$; Table 2$)$.

The result shows that SI, GCS, and FAST were all significant predictors of transfusion for earthquake patients. We use SI to assess shock degree due to its better performance to predict hemodynamic stability than either SBP or HR alone. ${ }^{3}$ In addition, GCS, a widely used score to accurately assess severity of traumatic brain injury, and FAST, a timely and unreplaceable parameter to diagnose abdominal hemorrhage, were confirmed to be useful to predict the transfusion requirement of people injured in earthquake. However, hemoglobin level was not performed significantly to be the possible predictor of transfusion, which was consistent with the observation of Michalsen, et al that it was difficult to use hemoglobin levels as guidance of transfusion therapy. In our study, patients who received transfusion therapy were more likely to have coagulation disorders. Previous studies have verified adverse outcomes of perturbations in blood coagulation, which could be exacerbated by the adverse immunologic effects of blood transfusion. ${ }^{4}$ The higher rate of admission to ICU and mortality could be explained by the higher severity of injury in earthquake patients who required transfusion treatment.

However, our study is also limited by its retrospective design, which prevented us to evaluate the therapeutic efficacy of transfusion further towards severely injured patients in earthquake. Furthermore, the missing records we excluded might lead to some bias. A large-scale, prospective research can be conducted to verify the certainty that appropriate transfusion therapy can improve outcomes of earthquake patients.

In conclusion, SI, GCS, and FAST are of use to indicate transfusion in earthquake patients. Coagulopathy, admission to ICU, and death are more likely to be found in patients who received transfusion therapy. Further study is required to explore the association of transfusion therapy and improved outcomes. 
References

1. Michalsen KS, Rognås L, Vandborg M, Erikstrup C, Fenger-Eriksen C. Prehospital transfusion of red blood cells and plasma by an urban ground-based critical care team. Prehosp Disaster Med. 2021;36(2):170-174.

2. Fujimori Y, Bouike Y, Nollet K, Miki H. Blood supply during Japan's 1995 Hanshin Awaji Earthquake. Transfus Apher Sci. 2016;55(2):201-204.
3. Maegele M, Brockamp T, Nienaber U, et al. Predictive models and algorithms for the need of transfusion including massive transfusion in severely injured patients. Transfus Med Hemother. 2012;39(2):85-97.

4. Ganter MT, Pittet JF. New insights into acute coagulopathy in trauma patients. Best Pract Res Clin Anaesthesiol. 2010;24(1):15-25. 